\title{
Morfoanatomía foliar y CaUlinar de HETEROPHYLLAEA PUSTULATA (RUBIACEAE)
}

\author{
LEAF AND STEM MORPHO-ANATOMY OF HETEROPHYLLAEA PUSTULATA \\ (RuBiaceAe)
}

\author{
Silvana C. Gallardo' (D) María M. Alemán ${ }^{1}\left(\mathbb{D}, Z^{2}\right.$ Zulma J. Avilés ${ }^{1}$, \\ Luis A. Colque Caro ${ }^{2,3}$, Juan F. Micheloud ${ }^{2,3}$ (id) y Olga G. Martínez ${ }^{1,4 *}$ (D)
}

1. Facultad de Ciencias Naturales, Universidad Nacional de Salta, Av. Bolivia 5150, (4400) Salta, Argentina.

2. Grupo de Trabajo de Patología, Epidemiología e Investigación Diagnóstica. Área de Sanidad Animal-IIACS, Instituto Nacional de Tecnología Agropecuaria, Argentina.

3. Facultad de Ciencias Agrarias y Veterinarias, Universidad Católica de Salta, Argentina.

4. Instituto de Bio y Geociencias del NOA (IBIGEO-CONICET), FCNUNSa, Salta, Argentina.

*martinezog@gmail.com

Citar este artículo GALLARDO, S. C., M. M. ALEMÁN, Z. J. AVILÉS, L. A. COLQUE CARO, J. F. MICHELOUD \& O. G. MARTÍNEZ. 2019. Morfoanatomía foliar y caulinar de Heterophyllaea pustulata (Rubiaceae). Bol. Soc. Argent. Bot. 54: 345-352.

DOI: http://dx.doi. org/10.31055/1851.2372.v54. n3.25358

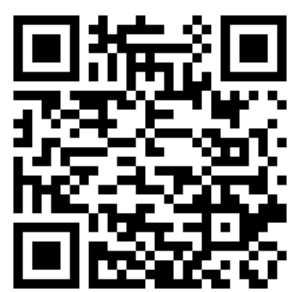

Recibido: 24 Abril 2019

Aceptado: 16 Agosto 2019

Publicado: 30 Septiembre 2019

Editora: Ana María Gonzalez (iD)

ISSN versión impresa 0373-580X ISSN versión on-line 1851-2372

\section{SUMMARY}

Background and aims: Heterophyllaea pustulata (Rubiaceae) grows in northwestern Argentina. It has livestock importance because it produces photosensitization in the cattle that consume it. That is why it is proposed to study the foliar and caulinar morpho-anatomy of the species in order to determine structural characters that facilitate the identification of the plant.

M\&M: Leaves and stems of young adult plants and seedlings obtained through in vitro cultures were taken and studied by conventional histological techniques. Images obtained with optical and scanning electron microscopy are presented.

Results: The results indicate that the studied species have morphological and anatomical characters similar to other species of Rubiaceae, although it presents others that were not previously described, such as the structure of the epidermis with striated cuticle and the anatomy of the stem.

Conclusions: It is found that the diagnostic characters that facilitate the identification of the plant are: microdenticulated margin of the lamina, epidermis with striated cuticle in leaves and young stems, simple eglandular trichomes, mesophyll with raphides and druses, in addition to the lysigenous cavities in all the organs of the plant.

\section{KEY WORDS}

Anatomy, lysigenous cavities, druses, toxic plants, raphides.

\section{RESUMEN}

Introducción y Objetivos: Heterophyllaea pustulata (Rubiaceae) crece en el noroeste argentino. Tiene importancia ganadera debido a que produce fotosensibilización en el ganado que la consume. Es por ello que se plantea estudiar la morfoanatomía foliar y caulinar de la especie con el objeto de determinar caracteres estructurales que faciliten la identificación de la planta.

M\&M: Se estudiaron hojas y tallos de plantas adultas jóvenes y plántulas obtenidas a través de cultivos in vitro, mediante técnicas histológicas convencionales. Se presentan imágenes obtenidas con microscopio óptico y electrónico de barrido.

Resultados: Los resultados indican que la especie estudiada comparte caracteres morfológicos y anatómicos con otras especies de Rubiaceae, aunque presenta otras que no fueron descritas anteriormente, tales como la epidermis con cutícula estriada y la anatomia del tallo.

Conclusiones: Los caracteres diagnósticos que facilitan la identificación de la especie son: margen microdenticulado de la lámina, epidermis con cutícula estriada en hojas y tallos jóvenes, tricomas simples eglandulares, mesófilo con rafidios y drusas, además de las cavidades lisígenas en todos los órganos de la planta.

\section{Palabras clave}

Anatomía, cavidades lisígenas, drusas, plantas tóxicas, rafidios.

\section{INTRODUCCIÓN}

El género Heterophyllaea Hook. f. (Rubiaceae), de origen sudamericano, cuenta con dos especies andinas $H$. lycioides (Rusby) Sandwith y $H$. pustulata Hook f., ambas conocidas como "cegadera" (Jørgensen et al., 
2014). H. pustulata, única especie que habita en pastizales de altura del noroeste de Argentina, entre los 1500 y 3000 m s.m. (Bacigalupo, 1993, 1996; Bacigalupo et al., 2008). Es un arbusto de 2-3 m de long., con hojas enteras y flores blancas con tubo rojizo-purpúreo, se identifica por sus "glándulas" globosas (Bacigalupo, 1993), oscuras a purpúreas, distribuidas en todo el cuerpo de la planta, a las que Tourn (1981) define como cavidades lisígenas, describe su estructura e indica que se encuentran en todos los órganos de la planta incluido los óvulos.

Esta especie es conocida por su toxicidad en ganado bovino, equino, ovino y caprino, su ingesta ocasiona dermatitis y queratoconjuntivitis por fotosensibilización (Micheloud et al., 2017). Núñez-Montoya et al., (2008) demostraron que las antroquinonas y soranjidiol presentes en las partes aéreas de las plantas son responsables de la fototoxicidad. La confirmación del diagnóstico en animales es el resultado de hallazgos clínicos, análisis bioquímicos e histológicos, junto con la localización e identificación de esta especie en las zonas de pastoreo (Micheloud et al., 2017).

En algunas especies tóxicas la identificación de fragmentos de la planta en el contenido gastrointestinal permite confirmar el consumo de la misma contribuyendo al diagnóstico (Zeinsteger et al., 2009). En estos casos la estructura y organización de la epidermis debido a la resistencia que el tejido ofrece a la acción química y mecánica de la digestión es de crucial importancia para identificar los fragmentos (Cid et al. 2003, 2011; Giannitti et al., 2012). H. pustulata es una planta tóxica de gran impacto productivo en algunas regiones de Argentina, por lo que el presente trabajo tiene por objetivo describir la morfoanatomía foliar y caulinar de plantas adultas jóvenes y plántulas con la finalidad de establecer caracteres morfológicos que faciliten su identificación en análisis microhistológico.

\section{Materiales y Métodos}

El material analizado proviene de plántulas obtenidas mediante cultivos in vitro y plantas adultas colectadas en ambientes naturales de Jujuy, Salta y Tucumán, también se consideraron las colecciones depositadas en el herbario MCNS (Thiers, en permanente actualización).
Material estudiado. ARGENTINA. Prov. Jujuy: Dpto. Capital, Tiraxi, 13-IX-1979, Vignale \& Brelia 306. Dpto. Ledesma, Qda. del Arroyo del medio, 700-1000 msnm, 5-VII-1999, Tolaba et al. 1794. Dpto. Tumbaya, Volcán, $1950 \mathrm{~m}$, 11-XII-2001, Mello \& Silva 1898. Prov. Salta: Dpto. Capital, San Lorenzo, cerro al Norte de la Quebrada, 1400-1700 msnm, 5-XI-1983, Novara \& Neumann 3812. Dpto. Chicoana, Qda. de Tilián, 1380 msnm, 30-I-1987, Ortín 63. Dpto. Guachipas, Paraje Las Juntas, V-2015, Micheloud s.n. (MCNS 13006). Dpto. La Caldera, Rio Potrero, Paraje el Zig-zag, 1800-1900 msnm, 15-X-1984, Novara 4321. Dpto. Metán, Sa. de Metán, Finca Cachari, cerca de campamento León, $1800 \mathrm{msnm}, 16-\mathrm{II}-$ 2007, Tolaba 4507. Dpto. Pampa Grande, 1800 msnm, 6-V-1942, Huntziker 489. Dpto. Rosario de Lerma, Corralito, $1540 \mathrm{msnm}, 14-\mathrm{XII}-2013$, Martínez \& Prado 3539. Prov. Tucumán: Dpto. Burruyacú, Burruyacú, 770 msnm, 30-III-2017, Micheloud s.n. (MCNS 13472).

Los órganos considerados para el estudio fueron hojas de plántulas de 10 a 20 días desde la germinación de las semillas, hojas de plantas adultas mayores de $3 \mathrm{~cm}$ de longitud y tallos jóvenes de plantas adultas.

Para la obtención de plántulas, las semillas fueron lavadas en agitación continua durante 30 minutos en una solución de agua corriente con detergente comercial, luego se desinfectaron con $\mathrm{NaClO}$ al $10 \%$ durante 4 minutos en agitación continua, y se sembraron en frascos con medio de cultivo de Murashige \& Skoog (1962) (MS) al $100 \%$ de su concentración salina y de vitaminas, al que se adicionó $6,0 \mathrm{~g} / \mathrm{l}$ de agar bacteriológico Britania $^{\circledR}, 15 \mathrm{~g} / 1$ de sacarosa, 1g/1 de carbón activado Biopack ${ }^{\circledR}$ y $0,1 \mathrm{~g} / \mathrm{l}$ de myo-inositol Merck ${ }^{\circledR}$, con $\mathrm{pH}$ 7. Los cultivos se llevaron a cámara de cría a una temperatura de $25 \pm 2^{\circ} \mathrm{C}$, $40 \%$ de humedad y fotoperiodo de $12 \mathrm{~h}$ luz durante 30 días.

El material disecado se recuperó hidratándolo en cajas de Petri con agua y detergente no iónico en estufa a $50{ }^{\circ} \mathrm{C}$ durante 48 y 72 hs. El material fresco y recuperado fue fijado en FAA $(1: 1: 8 \mathrm{v} / \mathrm{v} / \mathrm{v}$ formaldehido: ácido acético glaciar: alcohol etílico $80 \%$ ) para estudios con microscopia óptica (MO), y para estudios con microscopia electrónica de barrido (MEB) las muestras se fijaron en solución de $2,5 \%$ glutaraldheído, $2 \%$ buffer fosfato durante 


\section{S. C. Gallardo et al. - Anatomía vegetativa de Heterophyllaea pustulata}

72 hs. y deshidratadas en serie graduada de alcohol. Después de la fijación y deshidratación, las muestras se secaron en punto crítico con dióxido de carbono (Denton Vacuum DCP-1). Las secciones secas se fijaron en trozos de aluminio con cinta adhesiva de grafito de doble cara, recubiertas con oro (20-24 nm) en Denton Vacuum Desk IV.

Los cortes histológicos se realizaron a mano alzada. La tinción diferencial de tejidos se logró con Safranina (1\%) y Astra Blue (0,5\%) (Luque et al., 1996), y la ornamentación de la cutícula con Sudan IV (D’Ambrogio, 1986). La diafanización de hojas se realizó según la técnica de Dizeo de Strittmater (1973).

Se obtuvieron mediciones, considerando 15 a 20 muestras, con el software Leica LAS EZ V3.0. Los datos fueron expresados en promedio cuando la diferencia resultó menor, y para diferencias significativas se indican el menor y mayor valor. Las observaciones y obtención de imágenes se lograron con ML Leica DM500 con cámara incorporada y MEB JEOL Model JSM 6480 LV (Japan), del Laboratorio de Microscopía Electrónica de Barrido y Microanálisis (LASEM) de la Universidad Nacional de Salta.

\section{Resultados}

\section{Hojas en plantas adultas y plántulas}

Las hojas (Fig. 1A-D), en las plantas adultas y plántulas, son subsésiles, con un par de estípulas triangulares persistentes. Las láminas son simples, lanceoladas, en plantas adultas de 3-6(-10) x 0,5$1,5(-2) \mathrm{cm}$, de base decurrente, ápice cortamente acuminado y margen levemente revoluto, crenado, con microdentículos translúcidos en las escotaduras (Fig. 1E, F); en las plántulas, las láminas son ovadas de ápice agudo con microdentículos en todo el margen (Fig. 1G).

Las cavidades lisígenas son circulares, de $100-500 \mu \mathrm{m}$ de diámetro. En hojas adultas se encuentran hasta 250 unidades de color púrpura; en hojas de plántulas menores a un centímetro de longitud, hasta 30 unidades de color violáceo (Fig. 1C-D, G). Estas estructuras se evidencian desde los primeros días después de la germinación de las semillas.

La lámina, en vista superficial de plantas adultas y plántulas, tiene células epidérmicas con paredes anticlinales levemente sinuosas en cara adaxial (Fig. 1H) y marcadamente sinuosas en cara abaxial (Fig. 1I). La epidermis adaxial y abaxial, presenta cutícula estriada con estrías generalmente paralelas (Fig. 1J). Los tricomas son eglandulares, simples, unicelulares, de 30-50 $\mu \mathrm{m}$ de long. Las hojas son hipostomáticas, con estomas paracíticos (Fig. 1I, J).

En corte transversal, la lámina tiene epidermis uniestratificada con células isodiamétricas y anisodiamétricas, por debajo el mesófilo es heterogéneo, formado por parénquima en empalizada uniestratificado en cara adaxial y parénquima esponjoso 4-7-estratificado con células irregulares en cara abaxial (Fig. 2A, B). En el mesófilo son frecuentes cristales en forma de rafidios y drusas (Figs. 1G; 2C, D). Los haces vasculares son colaterales, rodeados por una vaina de células parenquimáticas incoloras y colénquima subepidérmico (Fig. 2E, F). Las cavidades lisígenas, tienen una pared con 2-4-estratos de células aplanadas, cubiertas por células grandes de 100 a $600 \mu \mathrm{m}$ dirigidas hacia la cavidad (Fig. $2 \mathrm{G}, \mathrm{H})$.

\section{Tallo joven en plantas adultas y plántulas}

En vista superficial del tallo, se observa epidermis con células anisodiamétricas de paredes anticlinales rectas, excepto en las áreas que corresponden a las cavidades lisígenas, donde las células son isodiamétricas (Fig. 3A, B). Los tricomas de los ejes son similares a los registrados en las hojas (Fig. 3C, D).

El tallo en corte transversal (Fig. 3C-G), presenta epidermis uniestratificada con células isodiamétricas, colénquima subepidérmico angular 1-3-estratificado y parénquima cortical clorofiliano 5-6-estratificado; el cambium 2-3-estratificado y un único haz vascular tipo sifonostela ectofloica con médula hueca (Fig. 3F, G).

Las cavidades lisígenas se encuentran en el parénquima cortical, con estructura semejantes a los descritos para las hojas (Fig. 3C, E).

El tallo de las plántulas es translúcido, con estructura semejante a la descrita, aunque tienen mayor densidad de tricomas en superficie y el haz vascular presenta médula parenquimática. Las cavidades lisígenas se evidencian como manchas violáceas semejantes a los observados en las hojas. 
Bol. Soc. Argent. Bot. 54 (3) 2019
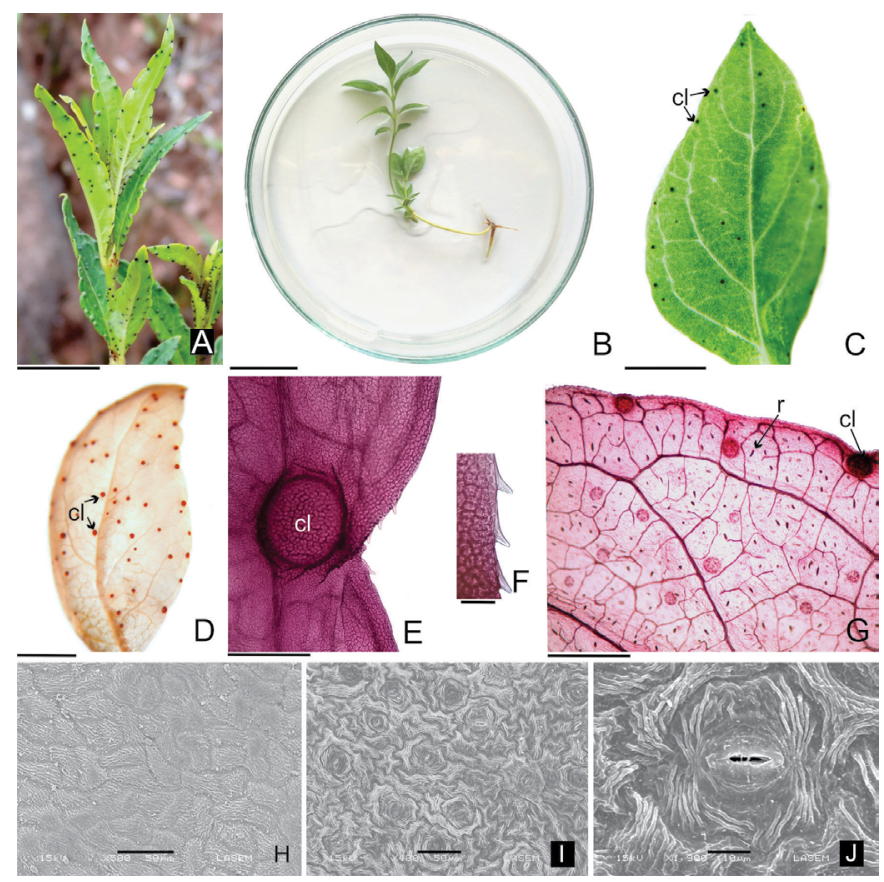

Fig. 1. Hoja de Heterophyllaea pustulata. A: Planta adulta. B: Plántula proveniente de cultivo in vitro. C: Lámina de plántula. D: Lámina diafanizada. E: Margen de hoja adulta con microdenticulos (MO). F: Detalle de microdentículos (MO). G: Lámina de plántula, diafanizada (MO). H: Epidermis adaxial (MEB). I: Epidermis abaxial (MEB). J: Detalle de cutícula estriada en epidermis abaxial (MEB). Abreviaturas= cl: cavidades lisígenas; r: rafidios. Escalas= A, B: 3 cm; C: 25 mm; D: 0,5 cm; E: $200 \mu \mathrm{m} ; \mathrm{F}: 30 \mu \mathrm{m}$; G: $1 \mathrm{~mm}$.

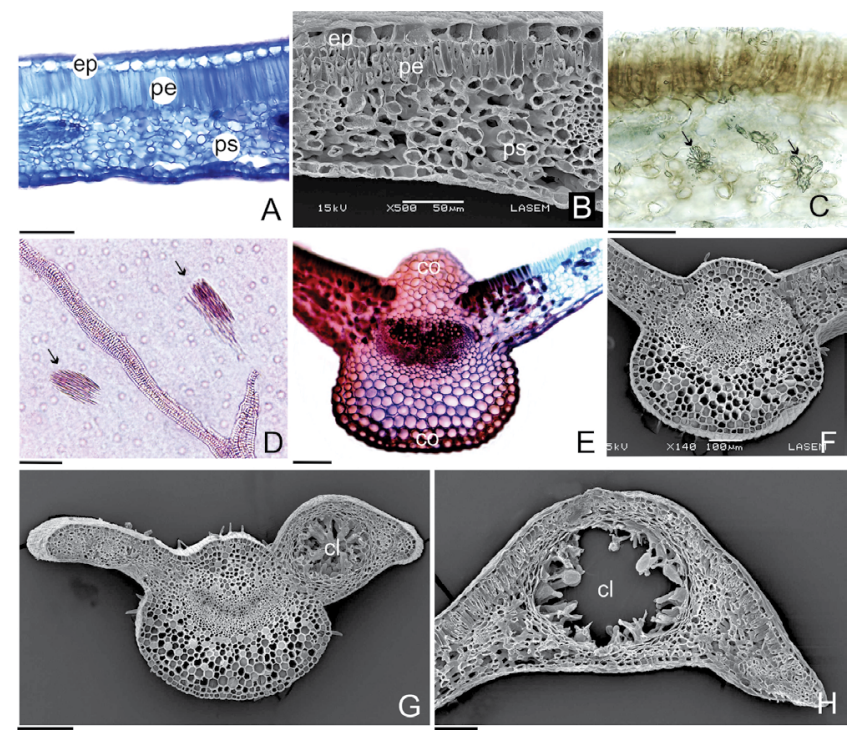

Fig. 2. Detalles del mesófilo de Heterophyllaea pustulata. A: Sección de lámina (MO). B: Sección de lámina (MEB). C: Drusas señaladas con flechas (MO). D: Diafanizado mostrando rafidios, señalados con flechas (MO). E: Haz vascular (MO). F: Haz vascular (MEB). G: Cavidad lisígena en mesofilo (MEB). H: Detalle de cavidad lisígena (MEB). Abreviaturas= ep: epidermis; cl: cavidad lisígena; co: colénquima; pe: parénquima en empalizada; ps: parénquima esponjoso. Escalas=A: $60 \mu \mathrm{m}$; C: $50 \mu \mathrm{m}$; D: $5 \mu \mathrm{m} ; \mathrm{E}, \mathrm{H}: 100 \mu \mathrm{m} ; \mathrm{G}: 200 \mu \mathrm{m}$. 

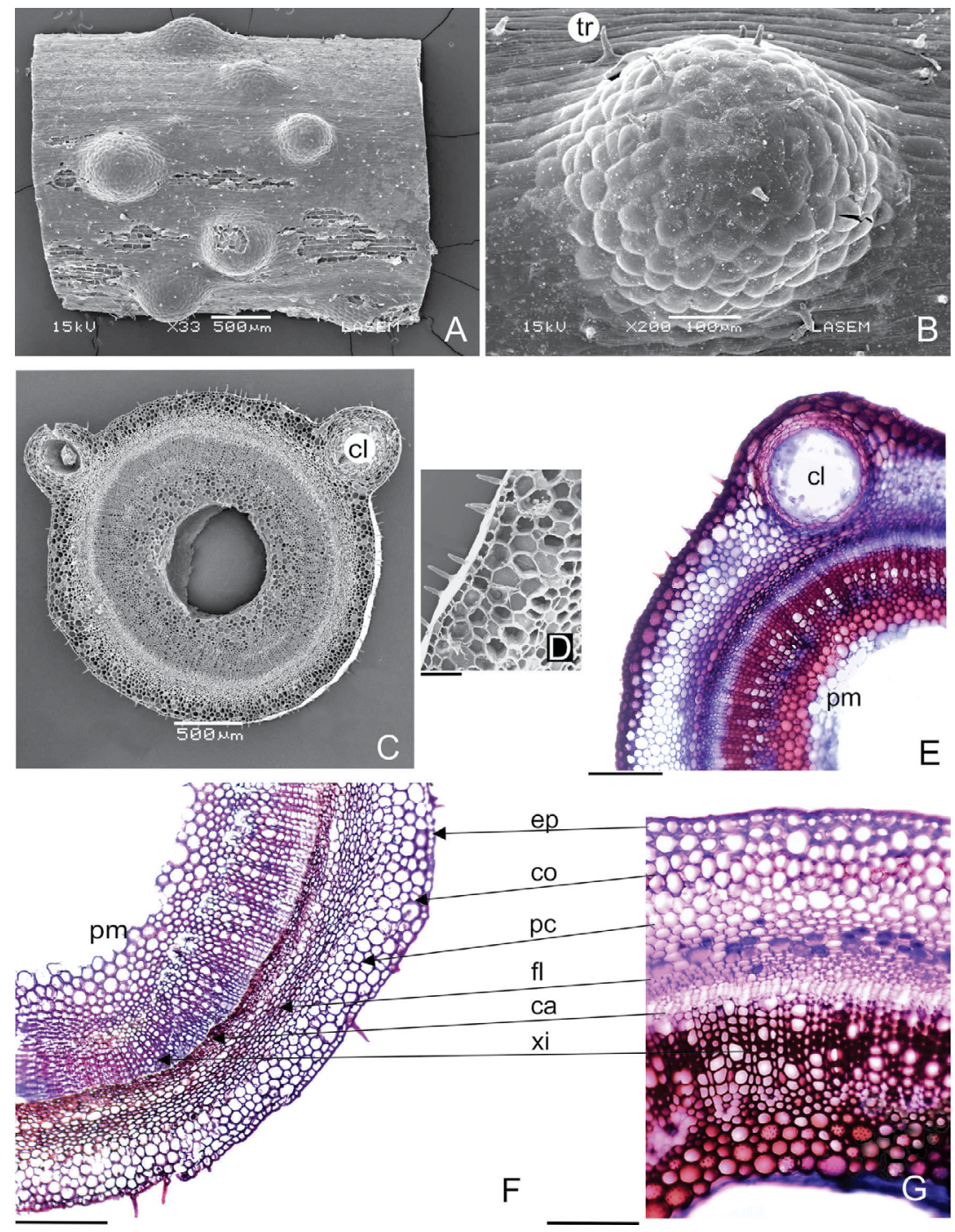

Fig. 3. Tallo de Heterophyllaea pustulata. A: Sector de tallo en vista superficial (MEB). B: Detalle de la epidermis sobre cavidad lisígena con tricomas (MEB). C: Sección de tallo (MEB). D: Detalle de tricomas (MEB). E: Transcorte de tallo (MO). F: Sección de tallo joven mostrando los tejidos (MO). G: Detalle de un sector del tallo (MO). Abreviaturas= ca: cambium; cl: cavidad lisígena; co: colénquima; ep: epidermis; fl: floema; pc: parénquima clorofiliano; pm: parénquima medular; tr: tricoma; xi: xilema. Escalas= D: $30 \mu m$; , F, G: $200 \mu \mathrm{m}$.

\section{Discusión y CONCLUSIONES}

Las características observadas en la anatomía de las hojas de Heterophyllaea pustulata referidos a epidermis uniestratificada con cutícula estriada, presencia de tricomas simples eglandulares, mesófilo dorsiventral con haces vasculares colaterales en forma de arco y hoja hipostomática con estomas paracíticos, son consistentes con los reportados para otras especies de Rubiaceae (Metcalfe \& Chalk, 1950; Mantovani et al., 1995; Vieira \& Gomes, 1995; Assis \& Giuliette, 1999; Quinteiro et al., 2006; Arruda et al. 2010; Alexandrino et al., 2011; 
Moraes et al., 2011; Zini et al., 2016; Campbell et al., 2018).

La variabilidad en la arquitectura de la cutícula en Rubiaceae constituye un carácter de valor diagnóstico utilizado para diferenciar géneros (Kocsis et al. 2004; Quinteiro et al., 2006; Alexandrino et al., 2011; Moraes et al., 2011), o especies (Moraes et al., 2009). En este trabajo, se describe por primera vez la ornamentación estriada de la epidermis de $H$. pustulata, se desconoce el valor diagnóstico a nivel específico por cuanto aún no se realizaron estudios anatómicos en la otra especie de Heterophyllaeae, H. lycioides, futuros trabajos deberían dilucidar este aspecto. Siendo la epidermis potencialmente importante para identificar las especies vegetales (Rosati, 1991) es fundamental conocer la organización de la cutícula y considerando su alta resistencia al proceso de masticación y digestión podría ser de utilidad en un análisis microhistológico.

La presencia de tricomas ha sido reportada para varias especies de Rubiaceae (Alexandrino et al., 2011), los mismos protegen a las hojas de la excesiva radiación, actúan a modo de barrera mecánica contra las temperaturas extremas, alta intensidad lumínica y perdida excesiva de agua (Werker, 2000; Bieras \& Sajo, 2009). Estas características corresponden al tipo de hábitat de la especie estudiada, dado que habita frecuentemente en lugares expuestos, principalmente de pastizales de altura.

La presencia constante de cristales es determinante para definir grupos taxonómicos (Webb, 1999), así se informa que son frecuentes en Rubiaceae, a veces presentan uno o más tipos según la especie o género (Arruda et al., 2010; Alexandrino et al., 2011; Moraes et al., 2011; Rodríguez Teixeira et al., 2016; Zini et al., 2016). En Heterophyllaea pustulata se observan dos tipos de cristales. Existen diversas funciones de estas estructuras, entre ellas Mantovani et al. (1995) consideran que podrían promover la defensa contra los herbívoros, Volk et al. (2002) que intervienen como nutrientes o reservas minerales de la planta, Pereira et al. (2003) que pueden actuar a modo de lentes, convergiendo los rayos luminosos hacia el interior del mesófilo.

En la estructura del tallo se destacan la epidermis con cutícula ornamentada con estrías y tricomas unicelulares, estos caracteres morfológicos no habrían sido descritos por Tourn (1981); los restantes tejidos subepidérmicos presentan un patrón de distribución característico de las dicotiledóneas (Fahn, 1990) y son frecuentes en otras especies de Rubiaceae.

Las cavidades lisígenas constituyen un carácter propio del género Heterophyllaea (Bacigalupo, 1993), aunque la composición química de su contenido es aún desconocida y por lo tanto no se puede asociar con los principios activos responsables de la fototoxicidad que producen las dos especies de éste género (Núñez-Montoya et al., 2006; Dimmer et al., 2017).

Los resultados indican que Heterophyllaea pustulata presenta una gran cantidad de caracteres anatómicos compartidos con otras especies de Rubiaceae, sin embargo el margen microdenticulado de las hojas, epidermis con cutícula estriada en hojas y tallos jóvenes, tricomas simples eglandulares, mesófilo con rafidios y drusas y cavidades lisígenas en todos los órganos de la planta, podrían facilitar la identificación de esta especie en estudios anatómicos y microhistológicos.

\section{Contribución de los Autores}

JFM y OGM planificaron el estudio, LAC y JFM realizaron trabajo de campo y seleccionaron las muestras. ZJA logró la obtención de plántulas mediante cultivos in vitro. SCG, OGM y MMA lograron las muestras histológicas, sus imágenes e interpretaciones. Todos los autores participaron en la redacción del manuscrito.

\section{Agradecimientos}

Este estudio fue financiado por el Consejo de Investigaciones de la Universidad Católica de Salta (Res. 1494/16, responsable JFM), proyectos Territoriales y Nacionales de INTA, y Consejo de Investigación de la Universidad Nacional de Salta (responsable OGM). Los autores agradecen el servicio técnico de la Ing. Silvia Blanco, del Laboratorio de Microscopía Electrónica de Barrido y Microanálisis de la Universidad Nacional de Salta, y a la Lic. Dalma Jaimez por su colaboración en el tratamiento de algunas muestras. 


\section{S. C. Gallardo et al. - Anatomía vegetativa de Heterophyllaea pustulata}

\section{Biblografía}

ALEXANDRINO, C. R., T. M. S. MORAES \& M. DA CUNHA. 2011. Micromorfologia e anatomía foliar de espécies de Rubiaceae do Parque Nacional de Itatiaia-RJ. Floresta e Ambiente 18: 275-288. https://doi.org/10.4322/floram.2011.048

ARRUDA, R. DO CARMO DE OLIVEIRA, D. M. SAITER GOMES, A. CARVALHO DE AZEVEDO, M. L. MAGALHÃES \& M. GOMES. 2010. Anatomia e micromorfologia foliar de seis espécies de Posoqueria Aublet (Rubiaceae). Rodriguésia 61: 505-518. http://dx.doi.org/10.1590/2175-7860201061311.

ASSIS, M. C. \& A. M. GIULIETTE. 1999. Diferenciação morfológica e anatômica em populações de "ipecacuanha" Psychotria ipecacuanha (Brot.) Stokes (Rubiaceae). Rev. Brasil. Bot. 22: 205-216.

BACIGALUPO, N. M. 1993. Rubiaceae. En: CABRERA, A. L (ed.), Flora de la Provincia de Jujuy. Colecc. Ci. Inst. Nac. Tecnol. Agropecu. 13: 375-437.

BACIGALUPO, N. M. 1996. Rubiaceae Juss. En L. NOVARA (ed.), Flora del valle de Lerma. Aport. Bot. Salta, Ser. Fl. 4: 1-52.

BACIGAlUPO, N. M., E. L. CABRAL \& C. M. TAYLOR. 2008. Rubiaceae. En: ZULOAGA, F. O. \& O. MORRONE (eds.), Catálogo de Plantas Vasculares de la República Argentina II. Monogr. Syst. Bot. Missouri Bot. Gard. 107: 2871-2920.

BIERAS, A. C. \& M. G. SAJO. 2009. Leaf structure of the cerrado (Brazilian savanna) woody plants. Trees 23: 451-471.

https://doi.org/10.1007/s00468-008-0295-7

CAMPBELL, G., M. SCHRAMM MIELKE, G. RODRIGUES RABELO, M. DA CUNHA. 2018. Key anatomical attributes for occurrence of Psychotria schlechtendaliana (Müll. Arg.) Müll. Arg. (Rubiaceae) in different successional stages of a tropical moist forest. Flora 246-247: 33-41. https://doi.org/10.1016/j.flora.2018.07.004

CID, M. S., T. A. LÓPEZ, C. YAGUEDDÚ \& M. A. BRIZUELA. 2003. Acute toxic plant estimation in grazing sheep ingesta and feces. J. Range Manage. 56: 353-357.

https://doi.org/10.2307/4004038

CID, M. S., C. INDURAIN, E. ODRIOZOLA, M. A. BRIZUELA \& M. LAUGE. 2011. Diagnose da ingestão de Asclepias mellodora St. Hil. por ovinos a través da análise micro-histológica de seu conteúdo digestivo. Pesq. Vet. Bras. 31: 111-116. https:/doi.org/10.1590/S0100-736X2011000200003
D’AMBROGIO DE ARGÜESO, A. 1986. Manual de técnicas en histología vegetal. Ed. Hemisferio Sur, Buenos Aires.

DIMMER, J. A., S. C. NÚÑEZ MONTOYA, C. S. MENDOZA \& J. L. CABRERA. 2017. Photosensitizing anthraquinones from Heterophyllaea lycioides (Rubiaceae). Phytochemistry 137: 94-100.

http://dx.doi.org/10.1016/j.phytochem.2017.02.003

DIZEO DE STRITTMATER, C. G. 1973. Nueva técnica de diafanización. Bol. Soc. Argent. Bot. 15: 126-129.

FAHN A. 1990. Plant Anatomy. Pergamon Press, Oxford.

GIANNiTTI, F., C. A MARGINEDA, M. S. CID, S. S. DIAB, N. WEBER, A. RODRÍGUEZ, C. M. CAMPERO \& E. R. ODRIOZOLA. 2012. Mortality of a captive axis deer (Axis axis) and a llama (Lama glama) due to ingestion of Wedelia glauca. J. Vet. Diagn. Invest. 20: 1-5. https://doi. org/10.1177/1040638712458784

JØRGENSEN, P. M., M. H. NEE \& S. G. BECK (eds.). 2014. Catálogo de Plantas Vasculares de Bolivia. Monogr. Syst. Bot. Missouri Bot. Gard. 127.

KOCSIS, M., J. DARÓK \& A. BORHIDI. 2004. Comparative leaf anatomy and morphology of some neotropical Rondeletia (Rubiaceae) species. Plant Syst. Ecol. 248: 205-218. https://doi.org/10.1007/s00606-002-0144-0

LUQUE, R., H. C. de SOUSA \& J. E. KRAUS. 1996. Métodos de coloração de Roeser (1972): modificado - e Kropp (1972) visando a substituição do azul de astra por azul de alcião $8 \mathrm{GS}$ ou 8GX. Acta Bot. Brasil. 10:199-212. https://doi.org/10.1590/S0102-33061996000200001

MANTOVANI, A., M. GOMES, D. M. S. GOMES \& R. C. VIEIRA. 1995. Anatomia foliar de Rudgea decipiens Mull. Arg. e R. macrophylla Benth. (Rubiaceae). Acta Bot. Brasil. 9: 247-261. https://doi.org/10.1590/S0102-33061995000200005

METCALFE, C. R. \& L. CHALK. 1950. Anatomy of the Dicotyledons. I: 1-724. Claredon Press. Oxford.

MICHELOUD, J. F., L. A. COLQUE-CARO, L. R. COMINI, J. L. CABRERA, S. NÚÑEZ-MONTOYA, O. G. MARTÍNEZ \& E. J. GIMENO. 2017. Spontaneous photosensitization by Heterophyllaea pustulata Hook. f. (Rubiaceae), in sheep from Northwestern Argentina. Trop. Anim. Health Prod. 49: 1553-1556. https://doi.org/10.1007/s11250-017-1354-0

MORAES, T. M. DA SILVA, C. F BARROS, S. J. DA SILVA NETO, V. M GOMES \& M. DA CUNHA. 
2009. Leaf blade anatomy and ultrastructure of six Simira species (Rubiaceae) from the Atlantic Rain Forest, Brazil. BioCell 33: 155-165.

MORAES, T. M. S., G. R. RABELO, C. R. ALEXANDRINO, S. J. da SILVA NETO \& M. DA CUNHA. 2011. Comparative leaf anatomy and micromorphology of Psychotria species (Rubiaceae) from the Atlantic Rainforest. Acta Bot. Brasil. 25: 178-190. https://doi.org/10.1590/S0102-33062011000100021

MURASHIGE, T. \& F. SKOOG. 1962. A revised medium for rapid growth and biossays with tobacco tissue culture. Physiol. Plant. 15: 473-497. https://doi.org/10.1111/j.1399-3054.1962.tb08052.x

NÚÑEZ-MONTOYA, S. C., A. M AGNESE, J. L. CABRERA. 2006. Anthraquinone derivatives from Heterophyllaea pustulata. J. Nat. Prod. 69: 801-803. https://doi.org/10.1021/np050181o

NÚÑEZ-MONTOYA, S. C., L. R COMINI, B. RUMIEVITTAR, I. M. FERNANDEZ, V. A. RIVAROLA \& J. L. CABRERA. 2008. Phototoxic effects of Heterophyllaea pustulata (Rubiaceae). Toxicon 51: 1409-1415.

https://doi.org/10.1016/j.toxicon.2008.03.011

PEREIRA, Z. V., R. M. S. A. MEIRA \& A. A. AZEVEDO. 2003. Morfoanatomia foliar de Palicourea longepedunculata Gardiner (Rubiaceae). Rev. Árvore 27: 759-767. https://doi.org/10.1590/S0100-67622003000600002

QUINTEIRO, M. M. C., D. CABRAL TEIXEIRA, M. G. MORAES \& J. G. SILVA. 2006. Anatomia foliar de Psychotria viridis Ruiz \& Pav. (Rubiaceae). Rev. Univ. Rural, Sér. Ciênc. da Vida 26: 30-41.

RODRIGUES TEIXEIRA, T., M. SOUZA PÁDUA, F. CASTRO, A. HORTÊNCIA. 2016. Leaf anatomy of Cordiera sessilis (Vell.) Kuntze (Rubiaceae). Acta sci., Biol. sci. 38: 355-364. https://doi.org/10.4025/ actascibiolsci.v38i3.29902

ROSATI, V. R. 1991. Caracteres epidérmicos foliares de valor diagnóstico en la identificación de plantas leñosas del Chaco occidental. AgriScientia 8: 41-53.
THIERS, B. 2018. Index Herbariorum: A global directory of public herbaria and associated staff. New York Botanical Garden's Virtual Herbarium. Disponible en: http://sweetgum.nybg.org/ih (acceso: junio 2018)

TOURN, G. M. 1981. Ontogenia y morfología de las cavidades lisígenas de Heterophyllaea pustulata (Rubiaceae). Bol. Soc. Argent. Bot. 20: 91-98.

VIEIRA, R. C. \& D. M. S. GOMES. 1995. Superfície da lâmina foliar de Psychotria nuda (Cham. \& Schltdl.) Wawra, P. leiocarpa Cham. \& Schldtl., P. stenocalyx Müll. Arg e P. tenuinervis Müll Arg. (Rubiaceae). Acta Bot. Brasil. 92: 263-270. https://doi.org/10.1590/S0102-33061995000200006

VOLK, G. M., V. J. LYNCH-HOLM, T. A. KOSTMAN, L. J. GOSS \& V. R. FRANCESCHI. 2002. The role of druse and raphide calcium oxalate crystals in tissue calcium regulation in Pistia stratiotes leaves. Plant Biology 4: 34-45. https://doi.org/10.1055/s-2002-2043

WEBB, M.A. 1999. Cell-mediated crystallization of calcium oxalate in plants. Plant Cell. 11: 751-761. https://doi.org/10.1105/tpc.11.4.751

WERKER, E. 2000. Trichome diversity and development. In: HALLAHAN D. L \& J.C. GRAY (eds.), Plant Trichomes. Advances in Botanical Research Incorporating Advances in Plant Pathology Vol. 31. Pp 1-35. San Diego, Academic Press. https://doi.org/10.1016/S0065-2296(00)31005-9

ZEINSTEGER, P. A., A. PALACIOS, P. LEADEN \& A. GURNI. 2009. Características micrográficas $\mathrm{y}$ digestión ruminal in vitro de una planta tóxica (Nerium oleander L., "laurel del campo") versus otra inocua (Eucalyptus camaldulensis Dehn, "eucalipto"). Rev. vet. 20: 3-9.

ZINI, A. DA S., S. MARTINS, M. L. TODERKE \& L. GODINHO TEMPONI. 2016. Anatomia foliar de Rubiaceae ocorrentes em fragmento florestal urbano de Mata Atlântica, PR, Brasil. Hoehnea 43: 173-182.

https://doi.org/10.1590/2236-8906-59/2015 